\title{
SOCIO-DEMOGRAPHIC FACTORS FOR HIGH-RISK PREGNANCY AMONG WOMEN IN RURAL AREA OF NAGPUR DISTRICT, CENTRAL INDIA
}

\author{
Ashok Rupraoji Jadhao1, Mahendra Dnyanobarao Gawde², Suresh Narayanrao Ughade 3 \\ 1 Professor and HOD, Department of Community Medicine, Indira Gandhi Government Medical College, Nagpur. \\ 2Medical Officer, PHC, Jaitapur, Ratnagiri, Maharashtra, India. \\ ${ }^{3}$ Assistant Professor, Biostatistics, Department of Community Medicine, Government Medical College, Nagpur.
}

\begin{abstract}
\section{BACKGROUND}

All pregnant women by virtue of their pregnancy status face some level of maternal risk. Some pregnancies are complicated by problems associated with mother's health. Most maternal morbidities could be prevented if women had access to appropriate healthcare during pregnancy. Identification of population specific factors for high-risk pregnancy will be useful for future health planning and thereby improve the management of high-risk pregnancy.

The study intended to find out prevalence of high-risk pregnancy and some related socio-demographic factors in high-risk pregnancy in rural area of Nagpur district, Central India.
\end{abstract}

\section{MATERIALS AND METHODS}

A community-based, cross-sectional study was conducted in Patansawangi PHC, district Nagpur. Pregnant women were called for pre-planned and pre-informed visit to ANC clinic (on Village Health and Nutrition Day) for examination. Data was collected consecutive sample of 214 pregnant women, who had 20 weeks and above gestation period during Aug 2014 to April 2015.

\section{RESULTS}

Prevalence of high-risk pregnancy was found to be $33.64 \%$ (95\% CI $27.31-39.97 \%$ ) in study subjects. Seventy two study subjects had one or more risk factor. Only 11 (5.14\%) study subjects had one risk factor, 52 (24.3\%) had two risk factors and 9 (4.21\%) had three risk factors. Prevalence of high-risk pregnancy was significantly more amongst age group less than 20 years. High risk pregnancy was more common among those having lower education. High risk pregnancy was found significantly associated with increasing parity.

\section{CONCLUSION}

Prevalence of high-risk pregnancy was found significantly higher amongst pregnant women with age less than 20 years, low education and increasing parity.

\section{KEYWORDS}

High-Risk Pregnancy, Socio-Demographic Factors, Rural Area, Gestation Period 20 Weeks and Above.

HOW TO CITE THIS ARTICLE: Jadhao AR, Gawde MD, Ughade SN. Socio-demographic factors for high-risk pregnancy among women in rural area of Nagpur district, Central India. J. Evolution Med. Dent. Sci. 2017;6(50):3847-3851, DOI: $10.14260 /$ Jemds/2017/831

\begin{abstract}
BACKGROUND
Every minute of every day, somewhere in the world and most often in a developing country, a woman dies from complication related to pregnancy or child birth. Nearly from all maternal deaths, most occur in the developing worldmaking maternal mortality the health statistic with the largest disparity between developed and developing countries. Pregnant women most commonly suffer from injury, infection or diseases. Pregnancy related complications are among the leading causes of death and disability for women aged 15 - 49 years in developing countries. ${ }^{1}$
\end{abstract}

Financial or Other, Competing Interest: None.

Submission 14-05-2017, Peer Review 11-06-2017,

Acceptance 17-06-2017, Published 22-06-2017.

Corresponding Author:

Dr. Ashok Rupraoji Jadhao

Professor and HOD

Department of Community Medicine,

Indira Gandhi Government Medical College,

Nagpur- 440018.

E-mail: ashokjadhao@yahoo.com

DOI: $10.14260 /$ jemds $/ 2017 / 831$

(c) (i) $\odot$
Every year there are an estimated 200 million pregnancies in the world. Each one of these faces the chance of an adverse outcome for the mother and for the baby. While risks cannot be totally eliminated once pregnancy begun, they can be reduced through effective, affordable, accessible and acceptable maternity care. Maternal risk is defined as the probability of dying or experiencing serious injury as the result of pregnancy or childbirth. All pregnant women by virtue of their pregnant status face some level of maternal risk. Data suggests that around $40 \%$ of all pregnant women need obstetric care to manage complications, which may potentially be life-threatening to mother or infant. ${ }^{2}$

Research has shown that small and affordable measures can significantly reduce the health risks that women face when they become pregnant. Most maternal deaths could be prevented if women had access to appropriate health care during pregnancy, childbirth and immediately afterwards. ${ }^{1}$

Families and communities have a major role to play in making that access possible and in protecting women's health through improved nutrition and the prevention of unwanted pregnancy. For safe pregnancy and childbirth, access to available services is a fundamental right for women. It is necessary to give special attention for high-risk group, which will reduce perinatal and maternal mortality and morbidity. 
Very few community-based studies in rural setting are available on this topic. It is needed to study high-risk pregnancy, which will be helpful for future health planning to improve the management of high-risk pregnancy.

Present study was undertaken to know the prevalence of high-risk pregnancies with associated socio-demographic factors in rural area of Nagpur district in Central India.

\section{MATERIALS AND METHODS \\ Study Design and Setting}

This present cross-sectional study was conducted in Nagpur district, Central India. The district has 13 rural and 1 urban block. From 13 rural blocks, one of the blocks was randomly selected in this district. There are 5 Primary Health Centres in the selected block. Out of them, Patansawangi PHC was purposively selected considering convenience and feasibility. The PHC is about $28 \mathrm{~km}$ away from study institution. It is situated in field practice area of Rural Health Training Centre of Study Institution; this area is surrounded by coal mines. This PHC is having 7 sub-centres and 29 villages with population of 48,418 . As per NFHS- $3^{3}$ the birth rate of selected district in rural area is 17.4 per 1000 population, hence expected pregnancies in a year will be 842 which fulfilled required sample size. The study was intended to find out prevalence of high-risk pregnancy and some sociodemographic factors in high-risk pregnant women. Study period extended from Aug 2014 to April 2015.

\section{Sample Size and Sampling}

Sample size estimated using formula $\mathrm{n}=3.8 \mathrm{pq} / \mathrm{d}^{2}$ with assumption prevalence of high-risk pregnancy $31.4 \%$ (Bharati et $\mathrm{al}^{4}$ ), acceptable margin of error $20 \%$ and level of significance $95 \%$ comes out to be 210 . Though estimated study sample size was 210 study subjects, but actually 214 study subjects were taken because all study subjects in last village were included in the study.

\section{Ethical Consideration}

The study protocol was approved by Institutional Ethics Committee (IEC). Informed consent was also obtained from each of the study participants after explaining the nature and purpose of the study and its potential benefits and expected duration of the study. Permission from District Health Officer was obtained for conducting the study.

\section{Methodology}

Pregnant women of 20 weeks and above gestation were selected for examination at Anganwadi in each village of subcentre and sub-centre were selected one after another till sample size was completed. Required sample size was completed in 6 sub-centres- Isapur $(n=41)$, Kothodi $(n=35)$, Pipla D Bangla $(n=23)$, Waki $(n=15)$, Sawarmendha $(n=18)$ and Malegaon $(n=82)$.

Pregnant women were called for pre-planned and preinformed visit to ANC clinic on Village Health and Nutrition Day (VHND) for examination with the help of Auxiliary Nurse Midwife (ANM)/ Multipurpose Worker (MPW), Anganwadi Worker (AWW) or ASHA. VHND is held every month on a fixed day of the month, where ANM/MPW deliver the MCH and nutrition services.
The pregnant woman who did not come to sub-centre or Anganwadi for ANC clinic was contacted with the help of ANM/MPW, AWW or ASHA at her home. All pregnant women who consented to participate were included in the study. Information regarding socio-demographic profile, relevant obstetric and medical history was collected in a predesigned and pretested proforma by interview technique. Any investigations study subject underwent from private sector were also reviewed, particularly Ultrasonography (USG).

Socio-economic status was determined using modified BG Prasad's socio-economic status scale. ${ }^{5}$ Physical examination of pregnant woman was done and parameters like weight, height and blood pressure etc. were recorded. Body weight ${ }^{6}$ was measured without shoes to the nearest $0.1 \mathrm{~kg}$ using the electronic weighing machine. Height ${ }^{6}$ of the subjects were measured using flat straight scale to the nearest $0.5 \mathrm{~cm}$. Blood pressure $^{7}$ was recorded by sphygmomanometer, three readings were taken 5 minutes apart and average of three readings was calculated. Haemoglobin was estimated by Sahli's method. ${ }^{8}$ Urine was checked for albumin and sugar by dipstick method. ${ }^{8}$ Test for random blood sugar was carried out by Accu-Chek Glucometer 9,10 ; if it was found more than $140 \mathrm{mg} / \mathrm{dL}$ then fasting blood sugar and 2-hour post meal blood sugar was tested the next day morning for confirmation of GDM.11

\section{Statistical Analysis}

Data was entered in MS-Excel (2013) and analysed using statistical software Epi-Info 7 (2014). Descriptive statistics (Percentage, mean, standard deviation, range) were used to summarise baseline characteristics of the study subjects.

Association between two categorical variables was analysed by using Chi-square test and Fisher exact test; $p$ value $<0.05$ was considered to be statistically significant.

\section{RESULTS}

Total 214 study subjects were registered for the study. Sociodemographic characteristics of study subjects are given in Table 1 . Mean age of study subjects was $24.42 \pm 2.72$ years with range 19 - 34. Most of the study subjects $(207,96.73 \%)$ were literate. Mean per capita income was Rs. $2471.86 \pm$ 2670.7 ranging from Rs. 370 to 20000/- per month. Mean height of mothers was $152.41 \pm 5.88 \mathrm{~cm}$ with range of 136 $168 \mathrm{~cm}$. Mean weight of pregnant women was $52.94 \pm 8.09 \mathrm{~kg}$ ranging from 35 to $84 \mathrm{~kg}$.

Prevalence of high-risk pregnancy was observed to be $33.64 \%$ (95\% CI 27.31 - 39.97\%). Seventy-two study subjects had one or more risk factors; $142(66.36 \%)$ study subjects were not having any risk factor. Only 11 (5.14\%) study subjects had one risk factor, 52 (24.3\%) had two risk factors and 9 (4.21\%) had three risk factors. Table 2 shows distribution of study subjects according to various risk factors.

Association of high-risk pregnancy with some sociodemographic factors has been shown in Table No. 3. Teenage pregnancy, educational status and parity were found to be significantly associated with high-risk pregnancy $(p<0.05)$. 


\begin{tabular}{|c|c|c|c|}
\hline \multicolumn{2}{|c|}{ Characteristics } & \multicolumn{2}{|c|}{$\begin{array}{c}\text { Study Subjects } \\
(\mathrm{n}=214)\end{array}$} \\
\hline & & \multirow{2}{*}{$\begin{array}{c}\text { No. } \\
14\end{array}$} & \multirow{2}{*}{$\begin{array}{c}\% \\
06.55\end{array}$} \\
\hline \multirow{4}{*}{ Age in Years } & $<20$ & & \\
\hline & $20-25$ & 141 & 65.89 \\
\hline & $26-30$ & 56 & 26.16 \\
\hline & $>30$ & 03 & 01.40 \\
\hline \multirow{3}{*}{ Religion } & Hindu & 183 & 85.51 \\
\hline & Buddha & 23 & 10.75 \\
\hline & Muslim & 08 & 03.74 \\
\hline \multirow{3}{*}{$\begin{array}{l}\text { Educational } \\
\text { Status }\end{array}$} & Above High School & 99 & 46.26 \\
\hline & Upto High School & 108 & 50.47 \\
\hline & Illiterate & 07 & 03.27 \\
\hline \multirow{2}{*}{$\begin{array}{l}\text { Occupational } \\
\text { Status }\end{array}$} & Homemaker & 209 & 97.66 \\
\hline & Working & 05 & 02.34 \\
\hline \multirow{5}{*}{$\begin{array}{c}\text { Socioeconomic } \\
\text { Status }\end{array}$} & $\mathrm{I}$ & 38 & 17.76 \\
\hline & II & 44 & 20.56 \\
\hline & III & 66 & 30.84 \\
\hline & IV & 56 & 26.17 \\
\hline & $\mathrm{V}$ & 10 & 04.67 \\
\hline \multirow{3}{*}{ Parity } & Nulliparous & 110 & 51.40 \\
\hline & One & 84 & 39.25 \\
\hline & Two & 20 & 09.35 \\
\hline \multirow[t]{4}{*}{ Height in cm } & $\leq 140$ & 06 & 02.80 \\
\hline & $141-150$ & 72 & 33.65 \\
\hline & $151-160$ & 117 & 54.67 \\
\hline & $>160$ & 19 & 08.88 \\
\hline \multirow[t]{2}{*}{ Weight in kg } & $\leq 40$ & 06 & 02.80 \\
\hline & $41-50$ & 92 & 42.99 \\
\hline
\end{tabular}

\begin{tabular}{|c|c|c|c|}
\hline & $51-60$ & 82 & 38.32 \\
\hline & $61-70$ & 30 & 14.02 \\
\hline & $>70$ & 04 & 01.87 \\
\hline \multicolumn{3}{|c|}{ Table 1. Characteristics of Study Subjects } \\
\hline \multicolumn{2}{|c|}{}
\end{tabular}

\begin{tabular}{|c|c|c|}
\hline \multirow{2}{*}{ Risk Factors } & \multicolumn{2}{|c|}{ Study Subjects $(n=214)$} \\
\hline & No. & $\%$ \\
\hline History of Caesarean Section & $31^{*}$ & 26.72 \\
\hline Teenage Pregnancy & 14 & 6.54 \\
\hline Malpresentation & 07 & 3.27 \\
\hline PIH & 06 & 2.80 \\
\hline Height $\leq 140 \mathrm{~cm}$ & 06 & 2.80 \\
\hline Oligohydramnios & 06 & 2.80 \\
\hline Weight $\leq 40 \mathrm{~kg}$ & 06 & 2.80 \\
\hline History of still birth & $05^{*}$ & 4.31 \\
\hline Associated diseases in pregnancy & 04 & 1.86 \\
\hline Prolonged pregnancy & 02 & 0.93 \\
\hline Age $>30$ yrs. in primigravida & 02 & 0.93 \\
\hline Gestational DM & 02 & 0.93 \\
\hline History of congenital anomaly & $02^{*}$ & 1.72 \\
\hline History of $\geq$ two abortions & $02^{*}$ & 1.72 \\
\hline Severe anaemia & 01 & 0.46 \\
\hline History of ectopic pregnancy & $01^{*}$ & 0.86 \\
\hline
\end{tabular}

*Out of total study subjects, 116 were second or more gravida

\begin{tabular}{|c|c|c|c|c|c|c|}
\hline \multicolumn{2}{|c|}{ Characteristics } & No & High-Risk Pregnancy & Low-Risk Pregnancy & Chi Square & $\mathbf{P}$ \\
\hline \multirow{2}{*}{$\begin{array}{c}\text { Age } \\
\text { (Years) }\end{array}$} & $<20$ & 14 & 14 & 0 & \multirow{2}{*}{$\begin{array}{c}\text { Fisher Exact } \\
\text { Test }\end{array}$} & \multirow{2}{*}{$0.0001^{*}$} \\
\hline & $\geq 20$ & 200 & 58 & 142 & & \\
\hline \multirow{2}{*}{ Religion } & Hindu & 183 & 65 & 118 & \multirow{2}{*}{1.987} & \multirow{2}{*}{0.158} \\
\hline & Other & 31 & 7 & 24 & & \\
\hline \multirow{2}{*}{ Educational Status } & $\begin{array}{l}\text { Upto High } \\
\text { School }\end{array}$ & 115 & 46 & 69 & \multirow{2}{*}{4.49} & \multirow{2}{*}{$0.03^{*}$} \\
\hline & $\begin{array}{c}\text { Above High } \\
\text { School }\end{array}$ & 99 & 26 & 73 & & \\
\hline \multirow[t]{2}{*}{ Socioeconomic Status } & $\begin{array}{c}\text { High } \\
\text { (I.II \& III) }\end{array}$ & 148 & 48 & 100 & \multirow[t]{2}{*}{0.155} & \multirow[t]{2}{*}{0.69} \\
\hline & Low (IV \& V) & 66 & 24 & 42 & & \\
\hline \multirow{2}{*}{ Parity } & Null & 110 & 30 & 80 & \multirow{2}{*}{4.116} & \multirow{2}{*}{$0.042^{*}$} \\
\hline & $\geq$ One & 104 & 42 & 62 & & \\
\hline
\end{tabular}

*Significance

\section{DISCUSSION}

Prevalence of high-risk pregnancy was 33.64\% (95\% CI 27.31 - 39.97\%). The finding is consistent with findings of some Indian and world studies like Bharati et $\mathrm{al}^{4}$ (31.4\%), Parmar D et $\mathrm{al}^{12}(27.89 \%)$, Oyibo P et $\mathrm{al}^{13}$ (35.1\%), Paudel I et $\mathrm{l}^{14}$ $(30.8 \%)$ and Nosseir S et $\mathrm{al}^{15}$ (27.7\%). Higher prevalence was found in study conducted by Ranmale D et al ${ }^{16}$ (57.8\%), Swains S et al ${ }^{17}$ (44.5\%), Deshmukh M et al ${ }^{18}(50 \%)$, Dutta P et $\mathrm{al}^{19}(44.6 \%)$, Kashani $\mathrm{E}$ et $\mathrm{al}^{20}(63.5 \%)$, Sam $\mathrm{F}$ et al $(63.5 \%),{ }^{21}$ while lower prevalence of high-risk pregnancy was found in studies like Mishra P et $\mathrm{al}^{22}(20 \%)$, Samiya M et $\mathrm{al}^{23}(15 \%)$ and Akthar $\mathrm{H}$ et $\mathrm{al}^{24}(4.5 \%)$.

Prevalence of high-risk pregnancy was significantly higher in age group of less than 20 years as compared to other age group $(\mathrm{P}=0.0001)$. Parmar $\mathrm{D}$ et al ${ }^{12}$ reported prevalence of high-risk pregnancy $(5.4 \%)$ in $<20$ years' age group as compared to $0.4 \%$ in age group of above 35 years.
Ranmale D et al ${ }^{16}$ shows higher proportion of high-risk pregnancy in < 19 years' age group (9.8\%) as compared to proportion of high-risk pregnancy in age group $>30$ years $(0.7 \%)$. Studies in other countries show similar findings. Akthar $\mathrm{H}$ et $\mathrm{al}^{24}$ carried out a study in Bangladesh which showed proportion of high-risk pregnancy in $<19$ years as $17.6 \%$ which was more than proportion of high-risk pregnancy in age $>30$ years $(8.8 \%)$. Paudal $\mathrm{I}$ et $\mathrm{al}^{14}$ conducted a study in Eastern Nepal and noticed that prevalence of high-risk pregnancy in $<20$ years $(11.5 \%)$ was more as compared to prevalence in $>35$ years' age group $(4.7 \%)$. But different finding was observed in study conducted by Bharati et al, ${ }^{4}$ i.e. as age of pregnant women increased more than 35 years there was increased risk of problems such as high blood pressure, gestational diabetes and complications during labour. The prevalence of high-risk pregnancy was $2.4 \%$ in group with age of $>35$ years. 
Present study noticed that prevalence of high-risk pregnancy was higher among study subjects of Hindu religion $35.5 \%$ as compared to prevalence in study subjects of other religion (22.5\%), but difference was not statistically significant $(\mathrm{P}=0.158)$. Similar finding was reported in studies carried out by Ranmale D et al, ${ }^{16}$ wherein the proportion of high-risk pregnancy was higher in Hindus (14.6\%) as compared to proportion in other religion (2.7\%). Sain S et $\mathrm{al}^{25}$ also showed higher proportion of high-risk pregnancy in Hindus (41.3\%) as compared to proportion in Muslims $(35.5 \%)$, but difference was not significant $(p=0.237)$. Paudal I et al $^{14}$ revealed prevalence of high-risk pregnancy in Hindus (31.3\%) and in other religion (29.6\%).

This study reveals that prevalence of high-risk pregnancy was higher in those who were educated upto high school completion $(40.0 \%)$ as compared to those who were educated upto graduation (26.2\%), and difference was found to be statistically significant $(\mathrm{p}=0.033)$. Similar findings were reported in studies carried out by Bharti et $\mathrm{al}^{4}(36.7 \%$, $24.9 \%)$, Sain $\mathrm{S}$ et $\mathrm{al}^{25}(78.2 \%, 21.8 \%)$, Ranmale D et $\mathrm{al}^{16}$ $(82.8 \%, 17.2 \%)$, Akthar $\mathrm{H}$ et $\mathrm{al}^{24}(52.7 \%, 47.3 \%)$ and Paudal I et $\mathrm{al}^{14}(58.3 \%, 41.7 \%)$ having prevalence of high-risk pregnancy in illiterate or lower education status and higher education status respectively. They showed higher prevalence of high-risk pregnancy in illiterate or lower education group as compared to higher education group. Education of women plays an important role in taking nutritious diet, proper antenatal check-ups and early recognition of symptoms of complications and seeking medical care. ${ }^{26}$ And also, education probably helps the women to understand the motivational efforts of the health professional for safe motherhood. All these factors might have contributed to the above findings in present study.

Current study reported proportion of high-risk pregnancy to be $36.3 \%$ in study subjects of lower socioeconomic status (class IV and V) as compared to those of upper socioeconomic status (class I, II, III) $32.4 \%$, but difference was not found to be statistically significant $(p=0.69)$. Similar results were observed in studies done by Bharati et al ${ }^{4}$ (33.3\%, 19.7\%), Sain $\mathrm{S}$ et $\mathrm{al}^{25}(74.6 \%, 25.4 \%)$, Ranmale D et al ${ }^{16}(88.1 \%$, $11.9 \%)$, Samiya $\mathrm{M}$ et $\mathrm{al}^{23}(14.5 \%, 0.5 \%)$ and Paudel I et al ${ }^{14}$ $(34.3 \%, 27.5 \%)$ had proportion of high-risk pregnancy higher in study subjects of lower socioeconomic status as compared to that in upper socioeconomic status study subjects.

In present study, $40.3 \%$ of high-risk pregnancy study subjects had parity more than one as compared to $27.2 \%$ of high-risk pregnancy in nulliparous study subjects, the difference being statistically significant $(p=0.042)$. But in contrast, in study conducted by Ranmale D et al ${ }^{16}$ (51.4\%) proportion of high-risk pregnancy was higher in nulliparous study subjects as compared to (48.6\%) that in study subjects with parity more than one. But difference was not significant $(\mathrm{p}=0.61)$. Also in study carried out by Akthar $\mathrm{H}$ et $\mathrm{al}^{24}$ in Bangladesh (17.6\%), proportion of high-risk pregnancy was higher in nulliparous pregnant women as compared to (6.6\%) proportion in multiparous pregnant women. Above result in the present study may be due to small sample size or better reporting.

\section{CONCLUSION}

Prevalence of high-risk pregnancy in rural area of Nagpur district was found to be $33.64 \%$ (95\% CI 27.31 - 39.97\%). Proportion of teenage pregnancy was $6.54 \%$ and elderly primi were $0.93 \%$. Prevalence of high-risk pregnancy was significantly more amongst age group less than 20 years. Literacy rate amongst study subject was $96.71 \%$. High risk pregnancy was more common among those having lower education. High risk pregnancy was found significantly associated with increasing parity. Study findings emphasise the need to modify some leading traditional and conventional risk factors for high-risk pregnancy like age, education and high parity.

\section{ACKNOWLEDGEMENT}

The authors would like to thank all local health workers ANM, MPW, AWW and ASHA for their help and coordination in data collection. Special thanks are due to study participants for their cooperation and valuable time.

\section{REFERENCES}

[1] Partnership for safe motherhood and new born health 2002. www.safemotherhood.org

[2] Graham W. Every pregnancy faces risks. Plan Parent Challenges 1998;(1):13-4.

[3] International Institute for Population Sciences (IIPS) and Marco International. National Family Health Survey (NFHS-3), India 2005-06. Vol. 1. 2007. http://www.emeraldinsight.com/doi/abs/10.1108/ij hcqa.2005.06218gab.007

[4] Bharti, Kumar V, Kaur A, et al. Prevalence and correlates of high risk pregnancy in rural Haryana: a community based study. Int J Basic Appl Med Sci 2013;3(2):212-17.

[5] Dudala SR, Arlappa N. An updated Prasad's socioeconomic status classification for 2013. Int J Res Dev Heal 2013;1(2):26-8.

[6] World Health Organization. WHO STEPS surveilance part 3: training and practical guides overview. 2008;3:3-1.

http://www.who.int/chp/steps/Part3.pdf?ua=1

[7] Whitworth JA, World Health Organization, International Society of Hypertension writing group. 2003 World Health Organization (WHO)/International Society of Hypertension (ISH) statement on management of hypertension. J Hypertens 2003;21(11):1983-92.

[8] Haematology and blood bank technique online module.

https://www.coursehero.com/file/11755014/Lesson $-27 /$

[9] User's manual blood glucose meter. Accu chek active Roche manufacturers 2006:1-47.

[10] Practice advisory blood glucose meter accuracy. American Association of Diabetes Educators 2013.

[11] World Health Organization. Diagnostic criteria and classification of hyperglycaemia first detected in pregnancy. Geneva: WHO, 2013:1-63. 
[12] Parmar D, Bhatkule P. A community based study of prevalence and pattern of morbidities associated with some components of RCH programme in population covered by PHC Patansawangi district, Nagpur. (MD Thesis). MUHS (Maharashtra University of Health Sciences), Nashik University. 2007.

[13] Oyibo PG, Ebeigbe PN, Nwonwu EU. Assessment of the risk status of pregnant women presenting for antenatal care in a rural health facility in Ebonyi State, South Eastern Nigeria. N Am J Med Sci 2011;3(9):4247.

[14] Paudel IS, Singh SP, Jha N, et al. High risk pregnancies and its correlates among the women of Eastern Nepal. Indian J Prev Soc Med 2008;39(3 \& 4):133-9.

[15] Nosseir SA, Mortada MM, Nofal LM, et al. Screening of high risk pregnancy among mothers attending $\mathrm{MCH}$ centers in Alexandria. J Egypt Public Health Assoc 1990;65(5-6):463-84.

[16] Ranmale D, Thakare S. Study of prevalence and pattern of risk factores in high risk pregnancies in women attending ANC clinic at RHTC Saoner. MUHS Nashik 2005.

[17] Swain S, Prakash A. Utilisation of referral services by high risk pregnant population in rural Varanasi. Indian J Matern Child Heal 1992;3(3):74-6.

[18] Deshmukh M, Fusey S, Yerawar N. Sickle cell anaemia complicating pregnancy. Indian J Obstet Gynaecol 1992;42(1):11-4.
[19] Dutta PK, Urmil AC, Gund SS, et al. Utilisation of health services by "high risk" pregnant women in a semi urban community of Pune -- an analytical study. Indian J Matern Child Heal 1990;1(1):15-9.

[20] Kashani E, Hassanzad A, Ameri MA. The rate of the prevalence of high-risk pregnancies and the results on pregnant mothers and the effect on parameters after the birth. Adv Environ Biol 2012;6(3):1319-24.

[21] Firozi S. The rate of the prevalence of high-risk pregnancies and the results on pregnant mothers and the effect on parameters after the birth. Int J Pharm Sci Res 2012;3(10):3735-41.

[22] Misra PK, Thakur S, Kumar A, et al. Perinatal mortality in rural India with special reference to high risk pregnancies. J Trop Pediatr 1993;39(1):41-4.

[23] Samiya M, Samina M. Identification of high risk pregnancy and its correlation with perinatal outcome. Indian J Pract Dr 2008;5(1):1-7.

[24] Akthar H, Sultana S, Siddique A. Neonatal out come in high risk pregnancy. Taj 2009;22(1):26-9.

[25] Sain S, Mukhopadhyay P, Saha TK, et al. Gestational diabetes: How risky are the mothers of rural Bengal, India. Glob J Med Public Heal 2012;1(6):1-9.

[26] Emiley BZ, Steven HW, Amber H. Understanding the relationship between education and health. A review of the evidence and an examination of community perspectives, Section V: emerging tools for studying population health, National Center for Children in Poverty 2014:347-84. 